\title{
Perceived Barriers to Youth entrepreneurship in Pakistan and Hungary
}

\author{
S. Z. A. KAZMI \\ Faculty of Economics and Business, University of Debrecen, Hungary, kazmi.zaheer@econ.unideb.hu \\ Faculty of Management Sciences, National University of Modern Languages, Islamabad Pakistan, \\ zabbas@numl.edu.pk
}

Abstract. Entrepreneurship brings enormous benefits. It generates employment and helps in social and economic development. Ventures created through the youth entrepreneurship have enormous benefits. They generate employment, reduce poverty and unequitable distribution of wealth. These ventures do also help in social, economic and technological development. However, the youth faces several barriers to entrepreneurship. This study explores the personal \& psychological, family related, institutional \& regulatory, cultural \& social, financial and market \& knowledge barriers faced by the youth of Hungary and Pakistan. Qualitative research methodology was applied. Interviews at micro and meso levels were conducted from the young entrepreneurs and university professors of Pakistan and Hungary. Results indicate that Pakistan and Hungary have almost similar levels of Personal \& Psychological barriers, however, the fear of failure is higher in Hungary than in Pakistan. Family related, cultural \& social and market \& knowledge barriers are higher in Pakistan for the youth entrepreneurship than Hungary. Institutional \& regulatory and financial barriers are at medium levels in Pakistan. For Hungary, these are at low levels. The study has important implications for researchers, academicians, policy makers and for the young aspiring entrepreneurs.

Keywords: Youth Entrepreneurship, entrepreneurship barriers, Pakistan, Hungary, Personal \& Psychological, Social \& Cultural, Financial, Family Related Barriers.

\section{Introduction}

Entrepreneurship was always there in practice in the communities and societies[1] It is as old as the phenomena of goods exchange and barter systems [2]. The poor, the sufferers of unequitable wealth, the oppressed have solutions in entrepreneurship. Non-Governmental Organizations (NGOs), international donors, the international financial institutions, politicians, policy managers at local, national, regional and international levels do also have interests in having more entrepreneurs. Academicians, economists, and social scientists are also imaginative and strive to develop entrepreneurs [3]. Young entrepreneurs, starting with humble initiatives grow up to successful ventures. They create the source of earning for themselves and many others. Additionally, bringing improvements in the social structure, employment, and economic growth. Entrepreneurship brings prosperity and social development. It encourages economic growth through healthy competition, generation and transmission of knowledge and diversity. It helps in creating jobs and enhances the per 
capita income[4]. The new business enterprises have a very important and positive impact on employment generation, poverty alleviation, and socio-economic development[5][6]. A suitable or reasonable combination of socioeconomic, religious and structural elements, besides the cultural and social capital are vital to the development of entrepreneurship[7]. This study has analysed different barriers to youth entrepreneurs both in Pakistan and Hungary at micro and meso levels. The study provides a comparison of Hungary and Pakistan regarding the perceptions of barriers as perceived by the youth of two countries. Entrepreneurship in the developing nations is hindered by the culture, socio economic conditions, and structural factors. The religion in Pakistan provides motivation for doing business as per the teachings of Islam [7]. Christianity is the majority's religion in Hungary. However, discussions with several university professors, $\mathrm{PhD}$ students and young entrepreneurs in Hungary during the last three years revealed that the role of church in developing entrepreneurship is not meaningful in terms of magnitude. This study provides unique analysis of the perceived challenges, restrictions, hindrances, problems or barriers (the terms are used interchangeably) to youth entrepreneurs in the two countries. Interviews from young entrepreneurs of Pakistan and Hungary were collected at the micro levels. Group interviews of entrepreneurs and university professors were collected at the meso levels. The preceding sections include brief literature about the barriers to entrepreneurship, methodology, results and discussions.

\section{Barriers to entrepreneurship}

Barriers to entrepreneurship are the perceptions framed in the minds of people, about starting and managing new businesses. These barriers create hindrances, as a result, the youth in particular remain confused and distressed. They do not take courage to start their ventures. "According to a recent survey, the most "stressed out" population in Pakistan are its millennials - those falling between the ages of 18 and 33 years old. This is a flaming red flag: Pakistan is the fifth largest 'young country' in the world. A recent United Nations Population Fund report makes the claim that out of 200 million people, 63 percent of Pakistan's population comprises of youth. Of these, 58.5 million are 20-to-24-year olds while 69 million are aged under 15. Stress can be fatal, and if the majority of youth is being pushed into stress, surely there is something wrong in the way that society is bringing up its youth?"[8]. Pakistan has enormous entrepreneurship potential. Entrepreneurial activity is however limited mainly for the barriers and, Socio-cultural constraints [7]. These barriers create hindrances and hurdles in the minds of youth. These hurdles in turn create fear, difficulty or negative perceptions regarding starting new business. A recent survey conducted by the Social Innovation Lab, a non-governmental organization however, reveals that "The entrepreneurial ecosystem of Pakistan has evolved tremendously in the past 3 years. With more and more incubators opening up, the industry seems like it is only going forward in the coming years"[9]. Pakistan has enormous entrepreneurship potential. Entrepreneurial activity is however limited mainly for the lack of Government policy ([10], Socio-cultural constraints [11]financial and other barriers [12]. Pakistan is a developing country and is one of the Next Eleven, the eleven countries that have a potential to be among the world's large economies in the 21st century[13]. 
The population of Hungary, as of 2017 is 9.798 million people, youth are only $10 \%$ of the population or 0.977 million young people between the ages of 18 to 33 years as per the Hungarian Central Statistical Office [14]. Hungry is striving for the economy based on innovations. Previous research and literature describes that the economy of Hungary has been struggling hard because of the rivalry between communism and capitalism[15]. The new era of liberalization and transformation from the old system has opened in 1990s with large privatization and transformation program called as "Kupa program" [16], [17]. The entrepreneurship in hungry, after change of political conditions, took many advantages. Different types of entrepreneurship such as educational entrepreneurship and entrepreneurship education started [18]. Hungary has also progressed well for entrepreneurship related to technology, horticulture and farming, and mainly in wholesale and retail trade [19].

The rate of venture creation or self-employment for Hungarian university students is high. Family support and family business background plays very important role in the graduates' intentions to become entrepreneurs [20]. It is naturally obvious that the students having family support will have comparatively better and stronger motivations for starting new businesses than those not having. Since, for those family support neutralize the family related barriers. Rather now they form positive perceptions of support from their families for starting the new ventures. Family background also helps the youth in forming positive perceptions regarding the new start-ups. They do also have an advantage over others in terms of better market knowledge, initial business training from their families and better networking options.

There are multiple barriers to entrepreneurship in different societies. Hungary and other European countries have three types of barriers in the broader sense; as discussed in the European Entrepreneurship Cooperation report. These are Regulatory barriers, cultural \& social barriers and the economic and financial barriers. The authors have furthermore discussed separately the barriers for disadvantaged of the society. These disadvantaged included women, ethnic minorities, disable and the young [21]. While discussing the barriers for youth. Authors highlighted lack of capital, less skills, having less ability to have supplier and marketing networks. Inadequate government support, funding problems, universities inability to develop and train entrepreneurs through entrepreneurship education are the vitally important barriers [22]. An empirical study conducted in Qatar investigated institutional and psychological barriers. The institutional barriers included financial, market and knowledge barriers. Whereas, attitude towards change, risk avoidance, fear of failure and stress avoidance were classified as psychological barriers [23]. Fear of failure, administrative hurdles and complexities and the lack of financial support were concluded as barriers to entrepreneurship in another study[24]. There are several other classifications of the barriers of entrepreneurship such as personal, family related, psychological, social, cultural, institutional, economic, political, financial, regulatory barriers.[23][25][26][27][28] [29].

For this study, the barriers to entrepreneurship, analysed from the two countries include personal or psychological, family related, cultural \& social, institutional \& regulatory, financial and market barriers. Personal barriers are conceptualized as risk avoidance, fear to failure and derive for status quo. Family related barriers are operationalized as lack of support from the family for a start-up and family expectations for government employment. Lack of role models, prestige and respect attached 
with the government jobs, self-evaluative in relation to social image, status consciousness and job security are also classified as cultural and social barriers. Institutional \& Regulatory barriers include complexities and hurdles related to registration, documentation and taxation procedures. Lack of financial support, high cost of capital and hurdles in securing loans are classified as financial barriers. Market or knowledge barriers are the lack of know-how related to the market, customers, suppliers and delivery channels. These also include lack of networking skills and abilities. Following section outlines the methodology for research, followed by results, discussion and conclusion.

\section{Method}

For this research, at the micro level of analysis, interviews were conducted from the professors of business education and young entrepreneurs from the two countries. An interview provides more space for clarification as well as confirmation of what has been said [30] [31]. At meso level, focused group discussions were managed with young entrepreneurs. In-depth individual and group interviews were managed for Pakistani and Hungarian young entrepreneurs and university professors. For the Pakistani entrepreneurs, telephonic and Facebook live interviews were conducted. Some of these interviews were also published on the Facebook and the YouTube channel [32][33][34][35][36]. For Hungarian professors and young entrepreneurs, the face to face interviews were conducted. Interviews from Pakistani professors and entrepreneurs were conducted in Urdu language, for Hungarians the language was English. Interviews from both the country respondents were recorded in video and audio and were listened again for qualitative data analysis. Interviews were semistructured, respondents were asked to reveal their success story in 20 to 30 minutes. Researcher asked questions regarding hurdles and barriers regarding the venture creation. Complete interviews lasted for about 40 to 65 minutes. Responses were categorized into specific themes as per the barriers to youth entrepreneurship[37]. From Pakistan and Hungary, interviews from 2 entrepreneurs, 2 professors and 1 one group interview from each country was conducted. Hence in total, there were 15 respondents for the study. 7 respondents from Hungary and 8 from Pakistan.

\section{Results and Findings}

Some of the responses from the respondents are presented here from both Pakistan and Hungary each under different barriers to youth entrepreneurship. On the bases of these responses, a comparative table of the barriers is presented.

\subsection{Personal and Psychological Barriers}

One of the respondents from Hungary reported that "[...] I wanted to be an employee of the multinational company. For business, it's difficult to sustain, I thought that I might not be successful. It is quite risky..."

A Pakistani young entrepreneur mentioned that "[...] before starting my business, I used to hesitate about business. I was reluctant to start a smaller business because I felt about my social status. In my opinion at that time, a government job was more respectable...I also feared to be failure..." 
Similar responses were revealed from the group interviews and the interviews with university professors of the two countries.

\subsection{Family Related Barriers}

Interviews from the Hungarian professors revealed that families usually do not compel the young graduates to have government or private jobs. However some families do prefer and influence them for jobs in multinational companies. As revealed by one professor "Our young graduates are usually not compelled by their parents for the jobs, however, some families do not extend the support for a start-up. Hence preference for the jobs does exist from the families..."

In case of Pakistan, one young entrepreneur reported in the interview "My parents wanted me to be a government officer, I had to struggle a lot to convince them for my start-up...."

\subsection{Cultural and Social Barriers}

Cultural and social barriers are not high in Hungary. The culture is individualistic. Society accepts the small start-ups by graduates as reported by a respondent "It's not a problem for Hungarian graduates that what people will think of them if they start a very small business. You can see the students confidently doing cleaning and other menial jobs, while residing in the same hostels. Status quo or social status and image are not a problem for most of Hungarians" It is the response of a Hungarian university professor.

A respondent from Pakistan, during the group discussion mentioned "there is lack of role models in our culture. Yes there are many successful entrepreneurs but their stories have not been broadcasted on mainstream media. Also, in our culture, because of job security and social image, prestige is attached with government jobs"

\subsection{Institutional and Regulatory Barriers}

In Pakistan these barriers have decreased over the time as noted by different respondents, such as "business registration, Intellectual property registration and other tax and regulatory issues are easier now in Pakistan than before. However, there is need to provide facilitation and awareness regarding these processes and for utility connections, energy crisis are yet great barriers"

For Hungary, these barriers are relatively low as one respondent said "Now we can register our business online, the process is very easy and fast than before. During the sociologist regime it was difficult and time taking"

\subsection{Financial Barriers}

In Pakistan, Financial barriers are relatively high as responded "while starting my business, I had many hurdles, especially, I needed the startup financing. My family was unable fund my startup, they also wanted me to be a banker. I had very small amount of saving, got some personal loan from my friends and uncle. I approached many banks, they needed my credit history and the asset as 
guarantee, and their interest rates were also high. For a new business, it was very difficult for me to arrange the initial investment.."

Financial barriers are comparatively low in Hungary: "Our aspiring entrepreneurs have many options for start-up funding, European Union Projects, Hungarian Government projects and soft loans etc."

\subsection{Market and Knowledge Barriers}

In Pakistan, these barriers are medium to high: "Youth has less awareness and knowledge about business. They lack the connections or networking. Absence of career counselling and low involvement of students in the industry as part time employees during study pose hurdles to this knowledge for starting business. The situation, in last couple of years has improved because universities have established the Entrepreneurship incubation centers. These centers help aspiring entrepreneurs from idea initiation to the early phases of their start-ups."

These barriers are low in Hungary "Usually, our students start some part time work after their secondary school. They also receive the business and commerce education in primary and secondary colleges. Yet they lack in networking..."

On the basis of responses from the individual and group interviews, the barriers for two countries are presented here in Table 1 in conclusive form:

\begin{tabular}{|l|l|l|}
\hline Barriers & Pakistan & Hungary \\
\hline Psychological or Personal & Medium to High & Medium to High \\
\hline Family Related Barriers & High & Medium \\
\hline Cultural and Social Barriers & High & Medium \\
\hline Institutional or Regulatory Barriers & Medium & Low \\
\hline Financial Barriers & Medium to High & Low to Medium \\
\hline Market and Knowledge Barriers & High & Medium \\
\hline
\end{tabular}

Table 1.: Conclusion of Interview Responses. Sources: Author's analysis on the basis of interviews.

\section{Discussion}

It is evident from the responses and data from this table that perception of barriers in Pakistan is relatively high in Pakistan than in Hungary. Hungary is member of the European Union. Since its inclusion in the EU and even before that, Hungary has received lot of attention from EU funding, research and development agencies. Additionally, Hungary is a developed country, having better infrastructure and other facilitations. However, during the author's interaction with several Hungarian professionals, it was revealed that most of the young Hungarians look for just EU funding and they concentrate less on the sustainability of their enterprises in the long run. Psychological or personal barriers are almost similar for the two countries. Fear of failure, one of the elements in these barriers is bit lower in Pakistan than that of Hungary. This can also be correlated with the Global Entrepreneurship Monitor data [38]. In the year 2011 the fear of failure rates for Pakistan and 
Hungary were 35.27 and 34.93 respectively. In 2012, this rate decreased to 31.24 for Pakistan, whereas it remained 34.28 for Hungary. In 2016, this rate jumped to 43.17 for Hungary. For Pakistan, the data is not available on Global Entrepreneurship monitor beyond 2012. However, according to UNDP as cited in a report[39] "23\% (approx. 12 million) of Pakistan's youth want to start their own business, but have noted that they "are clueless on the procedures \& requirements." Another report suggests that the entrepreneurship climate in Pakistan has improved and evolved tremendously over the past 3 years[9].

Family related barriers in Pakistan are relatively higher than those in Hungary. Mostly, in Pakistan, the families have a dream for their sons and daughters to have government jobs. Preference is attached to power driven jobs, such as bureaucracy, district management, police and armed forces etc. There does exist the preference for the banking and corporate sector jobs. There are few families who provide support and courage to the young aspiring entrepreneurs to establish their ventures.

Cultural and social barriers are high in Pakistan in comparison to Hungary. The job security culture dominates the majority youth preferences for employment. Sticking to the status quo fueled by the theory based multi class education system[40] is one of the main reasons for job seeking culture. Social-economic and structural forces play a significant role in suppressing social and cultural capital in rural areas of Pakistan, explaining the low level of entrepreneurship in these areas. Social and cultural capital requires a certain socioeconomic context for entrepreneurship to thrive[11]. The situation for regulatory and institutional barriers has improved a lot in both countries. In Hungary, these barriers are at a low level while in Pakistan at medium. Business registration, intellectual property rights registration and taxation documentation has become easier and convenient than before. However, getting the utility connections, like gas and electricity, still need to be streamlined. Entrepreneurs lot of barriers and problems because of the energy crisis [41]. Financial barriers in Pakistan are medium to high in Pakistan and low to medium in Hungary. Bank loans become difficult to obtain for the young graduates because of the collateral and high interest rates. However, university incubation centers and government financing schemes are bringing improvement. [9]. Market and knowledge barriers in Pakistan are relatively higher in Pakistan than Hungary. In Pakistan the entrepreneurship education is most of the times |"about entrepreneurship" wherein the students learn about the overview and concepts about business. Most of the examples, presentations and case-studies are meant for the students to put them in the situation of an employee. Hence consciously or unconsciously, he or she assumes the role of a manager - an employee. Hence they think like an employee than an employer. Also, in Pakistan, students, usually do not work until their masters degree completion or even until PhDs in some cases. In contrast, here in Hungary, usually students undergo student jobs after their secondary school. Hence, overall Hungary has less barriers for their youth than Pakistan for the youth entrepreneurship.

\section{Conclusion}

Barriers to youth entrepreneurship create negative perceptions and/or fear in the minds of young entrepreneurs. Hence they restrain from the venture creation, innovation and/or risk-taking or initiating. Results suggests that Personal and psychological barriers are at higher levels for the two 
countries. Proper counselling from the primary schooling, inclusion of the motivational success stories of entrepreneurs and small start-up projects can help in eradicating the problem of these barriers. The cultural \& social, family related and market \& knowledge barriers are relatively higher in Pakistan. The society of Pakistan has a colonial background as a developing country, being the colony of England. Gap between the rich and poor is usually higher. Access to university level is not easy or financially possible for everyone. These are some of the reasons behind social and cultural barriers. The education system needs a paradigm shift. We have been using the theory based education system. It needs to be more practically oriented - envisioned to solve the social and economic systems of the nation. Market \& knowledge barriers can best be solved through education system, familiarizing the successful entrepreneurs, the role models. Their stories need to be published in the form of books, in magazines, videos and on the mainstream print, electronic and social media. The electronic media in Pakistan is mainly focused on either news or entertainment. The effective media policy on educating the nation is required. These are some of the implications for practitioners, researchers, academicians and the policy makers.

\section{Limitations and Directions for Future Research}

The research has utilized qualitative data analysis. More generalizable research needs to be conducted with survey instrument for more empirical insights and generalizability. Pakistan has several education systems. Empirical data from different parts of Hungary and Pakistan can be gathered, as particularly, in Pakistan, there are many subcultures, so it is very important.

Causes to the barriers need to be addressed with rigorous research in the future. Longitudinal and/or experimental designs can be utilized for that purpose.

\section{References}

[1] W. J. (1990) Baumol Entrepreneurship: Productive, Unproductive, and Destructive. J. Polit. Econ., 98 (1) pp. 893-921.

[2] R. F. Hébert - A. N. Link (2006) Historical Perspectives on the Entrepreneur. Found. Trends ${ }^{\circledR}$ Entrep. 2 (4) pp. 261-408.

[3] S. M. Naqi (2012) Entrepreneurs. Third. Lahore: Naqi Hyder and Associates.

[4] M. H. Morris - D. F. Kuratko (2002) Corporate Entrepreneurship: Entrepreneurial Development within Organizations. Harcourt College Publishers, Fort Worth, TX.

[5] N. S. Amiri - M. R. Marimaei (2012) Concept of Entrepreneurship and Entrepreneurs Traits and Characteristics. Sch. J. Bus. Adm. 2 (7) pp. 150-155.

[6] S. Z. A. Kazmi - A. Nabradi (2017) New Venture Creation - the Influence of Entrepreneurship Education on Students' Behavior (a Literature - Review Based Study). Appl. Stud. Agribus. Commer. 11 (1-2) pp. 147-154.

[7] N. Muhammad - G. McElwee - L.-P. Dana (2017) Barriers to the development and progress of entrepreneurship in rural Pakistan. Int. J. Entrep. Behav. Res. 23 (2) pp. 279-295.

[8] The pakistani youth bulge: a ticking time bomb - Newspaper - DAWN.COM . 
[9] The entrepreneurial ecosystem of Pakistan has evolved tremendously in the past 3 years. With more and more incubators opening up, the industry seems like it is only going forward in the coming years, p. 1388958, 2018.

[10] M. Chemin (2010) Entrepreneurship in Pakistan: government policy on SMEs, environment for entrepreneurship, internationalisation of entrepreneurs and SMEs. Int. J. Bus. Glob. 5 (3) pp. 238-247.

[11] N. Muhammad - G. McElwee - L. P. Dana (2017) Barriers to the development and progress of entrepreneurship in rural Pakistan. Int. J. Entrep. Behav. Res., 23 (2) pp. 279-295.

[12] SMEDA [Online]. Available: http://www.smeda.org/index.php?option=com_content\&view=article\&id=7:state-of- smesinpakistan\&catid=15. [Accessed: 21-Apr-2018].

[13] GoldmanSachs, "Global Economics Paper No : 153 The N-11 : More Than an Acronym The N11 : More Than an Acronym," World, 2007.

[14] W. P. Day, “4/11/2018,” 2018.

[15] L. Szerb - Z. J. Acs - C. O'Gorman - S. Terjesen (2007) Could the Irish Miracle be Repeated in Hungary? Int. Small Bus. Econ., 28 pp. 123-142.

[16] J. Adam (1995) The transition to a market economy in Hungary. Eur. Stud., 47 pp. 989-1006.

[17] J. Svejnar (2002) Transition Economies: Performance and Challenges. J. Econ. Perspect., 16 pp. 3-28.

[18] P. Szirmai - K. Csapo (2006) From Student to Entrepreneur - A Hungarian Experience of Entrepreneurship Teaching.

[19] N. Etchart - A. Horváth - A. Rosandić - A. Spitálszky (2014) The State of Social Entrepreneurship in Hungary.

[20] A. S. Gubik - S. Farkas (2016) Student Entrepreneurship in Hungary: Selected Results Based on GUESSS Survey. Entrep. Bus. Econ. Rev., 4 (4) pp. 123-139.

[21] S. Martins - C. Couchi - L. Parat - F. Carmine - R. Doneddu - M. Salmon (2004) Barriers to entrepreneurship and business creation ECC-European Entrepreneurship Cooperation, no. November, pp. 1-49.

[22] S. Khayri - J. Yaghoubi - M. Yazdanpanah (2011) Investigating barriers to enhance entrepreneurship in agricultural higher education from the perspective of graduate students. Procedia - Soc. Behav. Sci., 15 pp. 2818-2822.

[23] B. Kebaili - S. S. Al-Subyae - F. Al-Qahtani (2017) Barriers of entrepreneurial intention among Qatari male students. J. Small Bus. Enterp. Dev., 24(4) pp. 833-849.

[24] P. Van Der Zwan - P. Zuurhout - J. Hessels (2013) Entrepreneurship education and selfemployment: The role of perceived barriers. no. January, pp. 1-25.

[25] S. Zaheer - A. Kazmi - M. B. Khan (2017) Critical Capability Concerns of School. Delhi Business Review, 18 (2) pp. 33-43.

[26] E. Auriol (2014) Barriers to formal entrepreneurship in developing countries. pp. 1-22.

[27] A. Michael Adewale (2015) Entrepreneurial development barriers in a developing nation: A case study of the Nigerian printing SMEs. Thesis.

[28] L. F. Klapper - L. Laeven - R. G. Rajan (2006) Entry Regulation as a Barrier to Entrepreneurship. J. financ. econ., 82 (3) pp. 591-629. 
[29] M. A. Roomi - G. Parrott (2008) Barriers to Development and Progression of Women Entrepreneurs in Pakistan. J. Entrep., 17 (1) pp. 59-72.

[30] B. Kebaili - S. Saeed Al-Subyae - F. Al-Qahtani - Z. Belkhamza (2015) World Journal of Entrepreneurship, Management and Sustainable Development An exploratory study of entrepreneurship barriers: the case of Qatar. World Journal of Entrepreneurship, Management and Sustainable Development, 11 (3) pp. 210-219.

[31] C. J. Christopher - J. Pole - R. Lampard(2002) Practical social investigation : qualitative and quantitative methods in social research. Prentice Hall.

[32] "https://www.facebook.com/531534621/videos/10157079083149622/?id=531534621.".

[33] "https://www.facebook.com/eshippakistan/videos/2036788483231373/.".

[34] "https://youtu.be/UAR5kmP7heQ."

[35] "https://youtu.be/Oy6R0bye_os.".

[36] "https://youtu.be/VeHEyNVSM-A." .

[37] T. W. Lee (1999) Using Qualitative Methods in Organisational Research. Thousand Oaks, CA.: Sage Publications.

[38] “GEM Global Entrepreneurship Monitor." [Online]. Available: http://www.gemconsortium.org/data. [Accessed: 18-Apr-2018].

[39] “i2i Ecosystem Report 2016 Final.pdf."

[40] S. Ali - E. Hafeez (2018) The Pakistani Youth Bulge : A. pp. 1-17.

[41] S. Hyder - R. N. Lussier (2016) Why businesses succeed or fail: a study on small businesses in Pakistan. J. Entrep. Emerg. Econ., 8 (1) pp. 82-100. 